\title{
Increasing Physical Activity of High Intensity to Reduce the Prevalence of Chronic Diseases and Improve Public Health
}

\author{
Tommy Aune Rehn*,a, Richard A. Winett ${ }^{\mathrm{b}}$, Ulrik Wisløff ${ }^{\mathrm{a}}$ and Øivind Rognmo ${ }^{\mathrm{a}}$
}

\author{
${ }^{a}$ K.G. Jebsen Center of Exercise in Medicine, Department of Circulation and Medical Imaging, Norwegian University of \\ Science and Technology, Trondheim, Norway \\ ${ }^{b}$ Center for Research in Health Behavior, Psychology Department, Virginia Tech, Blacksburg, VA, USA 24060
}

\begin{abstract}
High incidence and prevalence of chronic diseases, increasing obesity and inactivity as well as rising health expenditure represent a set of developments that cannot be considered sustainable, and will have dire long-term consequences given the increasing proportion of elderly people in our society. Based on a review of the experiences from previous large scale population-based prevention programs and the documented effects of increased physical activity and cardiorespiratory fitness on chronic diseases and its risk factors, we argue that increased physical activity, especially vigorous physical activity, is a major way to reduce the prevalence of chronic diseases and improve public health. We conclude that a coordinated population-based intervention program for improved health through increased physical activity in the entire population, with a special focus on high intensity exercise, urgently needs to be implemented nationally and internationally.
\end{abstract}

Keywords: Inactivity, physical activity, public health, overweight, intervention, prevention programmes, cardiorespiratory fitness, high intensity.

\section{INTRODUCTION}

Chronic diseases are the leading causes of death and disability worldwide. Levels of physical activity are decreasing and sedentary behaviours increasing with detrimental consequences on the prevalence of noncommunicable diseases (NCDs) such as cardiovascular disease, diabetes and cancer, as well as their risk factors such as hyperglycemia, hypertension and overweight [1]. According to The World Health Organisation [WHO], the prevalence of NCDs is accelerating globally, spreading across every region and pervading all socioeconomic classes [2,3]. The World Health Report from 2002 indicated that the morbidity, disability and mortality attributed to these diseases accounted for almost $60 \%$ of all deaths and $43 \%$ of the global burden of disease [2]. By 2020 their contribution is expected to rise to $73 \%$ of all deaths and $60 \%$ of the global burden of disease. Importantly, $79 \%$ of the deaths attributed to NCDs occur in the developing countries [2].

The biological risk factors for these chronic diseases are mainly caused by an unhealthy lifestyle (2). We here argue that a community-based prevention programme, with the aim to increase physical activity of high intensity, in all age groups within the population in a well-integrated manner, is

*Address correspondence to this author at the K.G. Jebsen Center of Exercise in Medicine, Department of Circulation and Medical Imaging, Faculty of Medicine, Norwegian University of Science and Technology, N-7491 Trondheim, Norway; Tel: +47 91709403; Fax: +47 728283 72;

E-mail: tommyrehn@yahoo.no a major way to control the risk factors for NCDs, and thereby improving public health and reducing health expenses.

\section{FOUR GENERATIONS OF POPULATION-BASED PREVENTION PROGRAMMES}

Carefully planned community-based prevention programmes may be an important vehicle to reduce the incidence and prevalence of chronic disease. Such populationbased strategies, aimed at reducing general risk factor levels through lifestyle and environmental changes, are considered to be more cost-effective and sustainable approaches for reducing the rates of mortality and morbidity than solely relying on individual-level interventions [4]. The rationale is that a moderate lowering of risk across a large number of people will have a bigger public health impact than large risk reductions among the few at high risk. An intervention that aims to achieve community-wide health improvements should therefore aspire to moderate risk reduction across the whole population. Community based interventions have advantages over narrowly targeted strategies because most people will be exposed to their positive effect. In addition, the costs of implementation are relatively low, large-scale health systems strengthening is not needed, and those already suffering from or at high risk of NCDs will also benefit [5]. Community based interventions aim to reduce the prevalence of one or more risk factors for chronic disease, and they typically use environmental change, public education and some degree of behavioural change strategies to promote lifestyle changes [6]. 
The North Karelia Project in Finland [7] together with the CHAD Project [8], the Stanford Three Community Project [9] and the Franklin Community CVD Health Program [10] provided the settings for the first large-scale community intervention programs in the early 1970s. The goals of these large scale interventions were to bring about social and health-oriented behavioural changes on several levels in the community - from the individual to the institutional and organizational levels. These first generation projects inspired later programs including the Stanford Five-City Project [11], the Minnesota Heart Health Project [12], and the Pawtucket Heart Health Project [13] in the United States.

The third generation projects evolved during the 1980s and 1990s with the goal of replicating the earlier trials but using fewer resources and targeted more specifically highrisk sub-populations. Among these studies was the Finnmark Intervention Study with a specific aim of changing cardiovascular risk factors through community-based intervention in a fishing community of Båtsfjord in the Norwegian Arctic [14]. The fourth generation studies that evolved after 2000 have focused more on discrete sub-populations such as the socioeconomic deprived, rural dwellers, elderly and ethnic minorities among others [4].

\section{OUTCOMES OF COMMUNITY-BASED PREVEN- TION PROGRAMMES}

One of the earliest and perhaps the most cited of all programmes is the North Karelia Project which was launched in Finland in 1972 in response to the local petition to get urgent and effective help to reduce the great burden of exceptionally high coronary heart disease (CHD) mortality rates in the area. In cooperation with local and national authorities and experts, as well as with WHO, the North Karelia Project was formulated and implemented to carry out a comprehensive intervention through the community organizations and the action of the people themselves. Comprehensive activities were used, involving health and other services, schools, innovative media campaigns, local media, supermarkets, food industry, and agriculture. The population's risk factors were greatly reduced, and consequently the age-adjusted CHD mortality rate among the 30-64 year old male population was reduced, from 1970 to 1995, by 73\% in North Karelia compared to $65 \%$ in all of Finland [15]. Very favourable changes were also shown with cancer and all-cause mortality and the general health of the population. After the original project period (1972-77), the experiences have actively been used for national comprehensive action.

The favourable results from North Karelia have later been questioned because subsequent analysis showed that the decline in CHD mortality in the rest of Finland was equivalent compared to North Karelia [16]. Furthermore, North Karelia had exceptionally high coronary heart disease mortality rates prior to the intervention, which probably offered a larger potential with respect to intervention effects compared to what could be expected in other communities. Also, several of the other large-scale cardiovascular communityintervention programs including the Minnesota, Stanford, and Pawtucket projects [11-13] showed beneficial changes in cardiovascular risk factors, but they too experienced difficulties in demonstrating significant differences compared with changes in the control communities. This is probably to some extent due to crossover of information, i.e. "contamination" effects. Also, results of previous community-intervention programs are often based on subjective self-reporting. The statistical differences will be diluted due to the potential biases [e.g., social desirability] of this method. One other explanation may be that during the last decades there has been an obvious secular trend for reductions in blood pressure, cholesterol levels and prevalence of cigarette smoking, which has in turn reduced the total cardiovascular risk burden [17]. Despite this secular trend, there is evidence that community-based interventions have an additional beneficial effect on these three risk factors $[7,9,18,19]$, although some studies did not support this (Table 1). The role of prevention programmes in initiating and accelerating the favourable events should nevertheless be recognised. The results with regard to effects on mortality rates $[10,11,20]$, body mass index [BMI] $[8,9,12,19]$, and physical activity $[12,14,21]$ are less consistent (Table $\mathbf{1}$ ).

\section{A RISING PANDEMIC OF OVERWEIGHT AND OBESITY}

Overweight and obesity are emerging as a pandemic [22$24]$ and imposing a large economic burden on society, responsible for about $80 \%$ of type 2 diabetes, 35\% of ischemic heart disease and $55 \%$ of hypertensive disease in Europe

Table 1. Studies Reporting Effect or no Significant Effect on Parameters Relevant to Public Health

\begin{tabular}{|c|c|c|}
\hline Parameter & Effect & No Effect \\
\hline \hline Mortality & {$[82,10,83,84]$} & {$[20,11,85]$} \\
\hline Estimated CVD risk & {$[82,9,10,86,87,84]$} & {$[11,20,13,85]$} \\
\hline Type II Diabetes & {$[88]$} & {$[85]$} \\
\hline Blood pressure & {$[7-11][83,85,18,88,14,89,87,84,19,90]$} & {$[91,12,13,86]$} \\
\hline Cholesterol levels & {$[7,9,10,83,18,88,86,89,87,19,90]$} & {$[11-14,93,89,89,94,95-97]$} \\
\hline Smoking & {$[7,91,8,9,92,10,18,88,84,85,19]$} & {$[91,9,12,18,14,88,89,93,94,85,97]$} \\
\hline Body mass index & {$[8,13,86,19,90]$} & {$[98,21,85,86,95,93,96,94]$} \\
\hline Physical activity & {$[12,88,14,97,19]$} & \\
\hline
\end{tabular}


[24]. According to WHO, the prevalence of obesity in Europe has tripled in the last two decades and the obesity trend is especially alarming in children and adolescents, as there are ten times as many obese in this age group in 2005 than in the 1970's [24]. In line with these trends, the latest figures from the Health Survey of Nord-Trøndelag (HUNT) in Norway showed that $60 \%$ of the population now can be classified as overweight, of which a third can be classified as obese. The proportion of obese men in Norway has tripled in the last 20 years (unpublished data, www.hunt3.no) and the incidence and prevalence of type 2 diabetes has consequently increased in Norway in recent decades. In 2004, diabetes prevalence in Norway was estimated based on several population-based surveys and it was found that between 90.000 and 120.000 Norwegians suffered from type 2 diabetes. It was estimated that as many people have an undiagnosed type 2 diabetes [25]. Unpublished data from the latest HUNT survey (HUNT 3) indicated that the incidence of type 2 diabetes continues to increase, especially for men. In the long run, this will probably result in an increase in diabetesrelated complications such as heart- and kidney disease. Extensive studies have demonstrated that both weight loss and physical activity can reduce the development and incidence of type 2 diabetes [26-28] and that this may be more effective than drug therapy [29].

\section{INACTIVITY}

Physical inactivity is now the fourth leading risk factor for global mortality [1]. Recent reports from England and the United States indicated that physical inactivity is the most common risk factor for chronic disease given that, when measured objectively, 95\% of the adult population does not comply with their national recommendations of physical activity [30,31]. In England, the estimated costs related to physical inactivity is five times higher than the costs related to smoking [32] and in 2000, the annual direct cost of physical inactivity in the USA was estimated as $\$ 76.6$ billion [33]. In view of the importance of inactivity for morbidity and mortality, it has recently been suggested that physical inactivity per se should be regarded as a disease [34]. In 2009, $83 \%$ of Norwegian 9 -year-olds and $52 \%$ of 15 -year-olds met the national recommendations for daily physical activity [35]. Norwegian boys in middle school and high school report 37-43 hours sedentary behavior in front of the PC or TV per week outside school hours in 2005, which represented a doubling from 1997. For girls the same age, the figure is 30 hours per week, also doubled from 1997 [36]. Generally, only about $20 \%$ of the Norwegian adult population (varies with gender and age) meets current recommendations for physical activity [35].

\section{EFFECTS OF PHYSICAL ACTIVITY}

Most previous community-based intervention studies have implemented multifactorial risk factor programs, including health education, to increase risk factor awareness, reduce smoking, and change dietary habits as well as screening to directly target blood pressure and cholesterol levels. Although several studies have estimated the effect of intervention on physical activity level and body weight, few of these have documented positive outcomes for these parame- ters (Table 1). This is probably in part due to the secular trend of a more sedentary lifestyle, but also attributable to the lack of thoroughly organized, integrated, long-term interventions to increase physical activity in the whole population. There is vast potential for reducing morbidity, premature mortality, and health care costs by increasing physical activity. Increased physical activity can actually reduce mortality similarly to smoking cessation [37]. In a recent study involving 416175 individuals, physical activity for $15 \mathrm{~min}$ a day or 90 min a week provided a reduction in all-cause and all-cancer mortality and extended an individual's lifespan for an average of 3 years [38]. This minimum amount of exercise was found to be applicable to men and women of all ages, even those with cardiovascular diseases or lifestyle risks.

It is well documented that increased physical activity reduces blood pressure [39] and cholesterol levels [40] as well as increases insulin sensitivity, thereby reducing the risk of developing type 2 diabetes [28]. Furthermore, regular physical activity may reduce body weight or prevent weight gain and bring about beneficial effects on the cardiovascular system [40]. Studies have documented that increased aerobic capacity [cardiorespiratory fitness; CRF] and physical activity leads to decreased morbidity and mortality, both in the healthy population [41-43] and in high prevalence patient groups as represented by patients with ischemic heart disease [44] chronic heart failure [45,46] and COPD [47]. Recent studies also showed that physical activity is associated with reduced risk of developing a variety of conditions and diseases such as metabolic syndrome, breast cancer, colon cancer, prostate cancer, pancreatic cancer, diabetes, high blood pressure, asthma, arthritis, osteoporosis and Alzheimer's disease by as much as 40-60\% [48] (Fig. 1). Individuals with at least average CRF for gender and age live longer than those with lower fitness, and even small changes in fitness can provide significantly increased life expectancy $[49,50]$. Interestingly, results from the HUNT survey including over 56000 men and women showed that one vigorous workout a week was associated with a $39 \%$ reduction in mortality for men and 51\% reduction in mortality for women [51].

\section{HOW TO EFFECTIVELY IMPROVE CARDIORES- PIRATORY FITNESS (CRF)?}

It is well documented that higher levels of physical activity and increased CRF are highly protective and are related to reduced all-cause mortality even in the face of other traditional risk factors [49,51-62]. Body mass index (BMI) can be high, but if people have at least moderate levels of CRF, the risk is lower, even compared with people with normal BMI but with lower CRF [63-65]. Interestingly, an innate low CRF is genetically accompanied by increased risk of cardiovascular disease (CVD) [66], and CRF seems to be more important than physical activity in controlling cardiovascular disease risk factors $[59,64,67,68]$. A recent study [68] emphasizes the very strong association of cardiovascular risk factors with real measures of CRF and a more modest association with self-reported level of physical activity. Even though there is a dose-response relation when it comes to the effect of physical activity on CVD and its risk factors [5658,69-71], it seems well documented that the intensity of the 


\section{Increased level of physical activity}

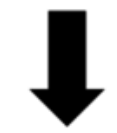

Reduced prevalence of:

- Overweight and obesity

- Diabetes type II

- Musculoskeletal disease

- Osteoporosis

- Cardiovascular disease

- Cancer

- COPD

- Alzheimer's disease

- Depression

- Anxiety

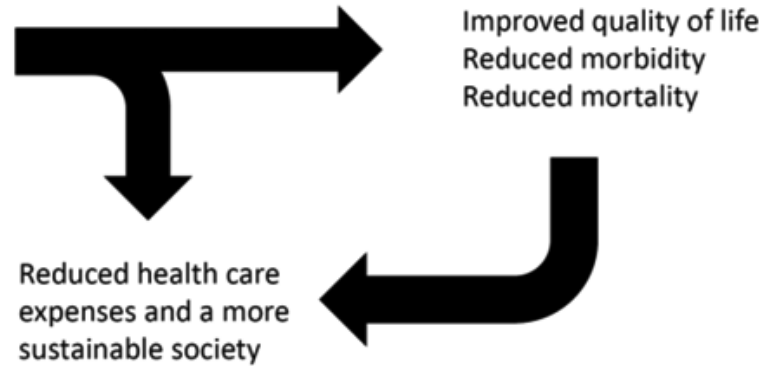

Fig. (1). Beneficial effects of increased physical activity in the population.

physical activity performed is of particular importance for its preventive effect [51,59,72,73]. As recently reviewed [74], the effects of high intensity training, such as interval training, is superior to that of training with low and moderate intensity. This indicates that an intervention on physical activity should focus on increasing CRF in the general population and include a fair proportion of physical activity with high intensity.

Interval training may be an effective way to implement high exercise intensity to increase aerobic exercise capacity and improve health. The principle of interval training is based upon high intensity exercise bouts that are alternated by periods of lower intensities that allow for recovery, making a person able to reengage in high-intensity exercise. Such "intervals," when repeated several times, may maximize the training stimulus, as it is the accumulated time in the high intensity exercise zone that is believed to determine the outcome of the training. Informal comments from exercising subjects in our study group indicate that both healthy individuals and patients find it motivating to have a varied procedure to follow during each training session, whereas those performing moderate exercise find it "quite boring" to walk continuously during the whole exercise period. Our results show that the cardiovascular beneficial effects of aerobic exercise training are intensity dependent, with superiority of high aerobic intensity to low to moderate intensity. This is found both in patients with established heart disease such as CHD and even in heart failure [73,75]. There seems to be a true dose-response relationship regarding exercise intensity for improving exercise capacity, where high-intensity exercise training conferring about twice the benefit of moderateintensity exercise training [74]. High-intensity exercise training may also be required for an effect to occur on left ventricular structure and function. Moreover, in patients with heart failure, a reversal of the pathological remodelling and systolic and diastolic improvements were observed only after high-intensity exercise training [73].
Winett et al. have previously demonstrated that most of the effect of aerobic training is attained when the highintensity threshold is passed for only a few minutes [76]. This implies that the time for effective exercise can be substantially reduced. In fact, a recent study [77] evaluated the effects of one single 4- minute aerobic interval work-bout (1AIT) carried out 3 times per week for 10 weeks. The subjects were healthy, young men, slightly overweight and the results were compared with a $4 \times 4$ minute training protocol (4-AIT) conducted 3 times per week in the same period. There were no differences between the 1-AIT group and the 4-AIT group with respect to effects on maximal oxygen uptake (VO2max), stroke volume, arterial blood pressure, body fat and fasting glucose levels. In addition, work from Martin Gibala's group [78] suggests that a number of metabolic adaptations usually associated with traditional high-volume endurance training can be induced faster than previously thought with a surprisingly small volume of high intensity exercise.The available data on high intensity training and interval training so far are promising in both healthy individuals and patients, showing that even people with serious risk factors such as CHD patients, can tolerate and respond to this type of exercise training [74]. When comparing almost 200000 training sessions involving both moderate- and high intensity training, the risk of major complications does not seem to be elevated in CHD patients performing high intensity exercise compared to moderate exercise (unpublished data). We thus believe there is sufficient empirical support to use high intensity exercise to promote health in a coordinated population-based intervention to maximize CRF. In line with this, WHO recently published a report on global recommendations on physical activity for health [1], which emphasizes that central role of high intensity exercise. As for the type of training, duration, intensity and total training load per week, we believe the guidelines presented in this report should form the basis of such a population-based intervention (Table 2). 
Table 2. WHO Recommendations on PA for Health, Adapted from WHO Report 2010 (1]

\begin{tabular}{|c|c|}
\hline \multicolumn{2}{|r|}{ 5-17 Years Old } \\
\hline 1. & At least 60 minutes of moderate to vigorous-intensity PA daily \\
\hline 2. & PA above 60 min daily will provide additional health benefits \\
\hline 3. & Most of the daily PA should be aerobic. Vigorous-intensity PA should be incorporated at least 3 times a week \\
\hline \multicolumn{2}{|r|}{ 18-64 Years Old } \\
\hline 1. & $\begin{array}{l}\text { At least } 150 \text { min of moderate-intensity aerobic PA a week, or at least } 75 \text { min of vigorous-intensity PA a week, or an equivalent combination of } \\
\text { moderate- and vigorous-intensity activity }\end{array}$ \\
\hline 2. & For additional health benefits, this should be increased to 300 and 150 min respectively \\
\hline 3. & Aerobic activity should be performed in bouts of at least 10 min duration \\
\hline 4 & Muscle-strengthening activities should be done involving major muscle groups on 2 or more days a week \\
\hline \multicolumn{2}{|r|}{65 Years and Above } \\
\hline & $\begin{array}{l}\text { At least } 150 \text { min of moderate-intensity aerobic PA a week, or at least } 75 \text { min of vigorous-intensity PA a week, or an equivalent combination of } \\
\text { moderate- and vigorous-intensity activity }\end{array}$ \\
\hline & For additional health benefits, this should be increased to 300 and 150 min respectively \\
\hline & Aerobic activity should be performed in bouts of at least 10 min duration \\
\hline & Those with poor mobility should perform PA to enhance balance and prevent falls on 3 or more days a week \\
\hline & Muscle-strengthening activities should be done involving major muscle groups on 2 or more days a week \\
\hline & Those who cannot meet these recommendations should be as physically active as their abilities and conditions allow \\
\hline & ysical activity \\
\hline
\end{tabular}

\section{A CALL FOR INCREASED PHYSICAL ACTIVITY}

We believe overweight/obesity and physical inactivity represent a major future health challenge to the modern society, and that a large scale, community based prevention programme to increase physical activity in all age groups in a well integrated manner is required. The question today is not whether physical activity per se has the beneficial effects described above. The question is if and how a sufficient level of high intensity physical activity can be attained in all strata of the population. A coordinated population-based intervention could demonstrate positive effects of increased physical activity on public health by reducing the prevalence of NCDs, reducing medical expenses and mortality, as well as increasing work capacity in the population, which in turn would reduce socio-economic costs. This could form the basis for national and international implementation of health policies and programmatic measures to ensure sustainable development and stability.

\section{KEY CONCEPTS OF SUCCESSFUL INTERVENTION}

One of the lessons from previous large community health interventions is that when you try to do too much with too many people, the focus of the program may be lost, the dose per person is low, and the outcomes are often disappointing. When reviewing the literature in the field of populationbased prevention, the general consensus is that the majority of projects have only modest impacts on the prevalence of CHD risk factors at the community level [4]. To achieve an effective intervention, one has to do the right thing, and do enough of it. This means that it is waste of resources if, for example, a correct preventive dose is used but in an interven- tion that has a too wide focus. Therefore, important considerations are whether interventions are doing the right things for the right people, in the right place and at the right time [4]. To achieve success, the unique contextual [social, physical, economic, political and cultural] features of the target population need to be identified instead of solely replicating previous interventions in a new setting [79]. A recent scientific statement from the American Heart Association [80] provided evidence-based recommendations on how to implement interventions to promote physical activity. This statement emphasized the importance of cognitivebehavioural strategies and the necessity of changes in health care policy in order to promote and make it feasible for the general population to follow the recommendations on physical activity. Based on research from the past decades, knowledge has been gained on how to effectively reduce the major physiological risk factors on an individual level through lifestyle modifications using exercise training. We believe that the time to introducing high-intensity exercise to the whole community has come.

A population-based intervention to increase physical activity in the population should, to the extent possible, make use of existing community structures such as schools, workplaces, sport clubs and the existing health care system, particularly the general practitioners. One should aim at increasing physical activity in all age groups by providing optimal conditions for each subpopulation. For the younger age groups this type of physical activity could for example be implemented in the school curriculum. For the middle aged and elderly training could be organized at workplaces, within sport clubs or by local authorities. In contrast to most previous large-scale population-based intervention programs, we 
believe that introducing a single focus, namely increased physical activity with high exercise intensity, will increase the chance of a successful intervention irrespective of whether or not the current recommendations on exercisedose is being fulfilled. For long-term prevention, it is crucial that the intervention has an effect on the already inactive individuals, regardless of age. As early intervention has the greatest potential in a long perspective, one should focus strongly to intervene from childhood and adolescence. This will be particularly challenging and requires simple and feasible measures and activities. Various ways to implement brief periods of high-intensity physical activities throughout the day for all age groups to increase the magnitude of the exercise response should be devised. Use of the social structures described above, combined with personalized recommendations that are perceived as affordable and feasible for the individual, organizations and communities, and the society, and with opportunities for follow-up, will be important.

Evaluating the effect of the various measures, and adjust, remove or introduce measures accordingly is of utmost importance. In addition to results in the short-term that can guide the choice of measures at national level, one should also evaluate the effects over several decades, to fully assess the effect of primary prevention from young age. Thorough documentation of intervention effects, including controlling for national and international trends, necessitates a comparison with national registries on cause of death and prevalence of non-communicable diseases. Comprehensive national registries would also provide background knowledge so that intervention measures could be customized to the contextual features of the target population.

Furthermore, although having received far less attention in disease prevention, resistance training should be included in a community-based prevention programme, as it has been shown to be likely as effective as aerobic training in lowering risk for several chronic diseases [81]. In addition, resistance training is important to increase, maintain or slow the loss of muscle mass. Thus, resistance training offers an antisarcopenic effect which is of particular importance given the aging population. As an integral part of a communitybased prevention programme, resistance training should be simple, brief and feasible in order to have large public health relevance.

\section{CONCLUSION}

High incidence and prevalence of chronic diseases, increasing obesity and inactivity as well as rising health expenditure plus the increasing proportion of elderly people in our society represent a set of developments that cannot be considered sustainable and will have dire long-term consequences. Physical inactivity is among the lifestyle factors most strongly associated with a low level of exercise capacity, all-cause mortality and death from cardiovascular disease. Increased physical activity, and in particular increased CRF, has a beneficial effect on all risk factors for chronic disease and premature death. A coordinated populationbased intervention program for improved health and reduced health expenses through increased physical activity in the entire population urgently needs to be implemented nationally and internationally.
A special focus on high exercise intensity should be emphasized as the health benefits seem to be larger with high intensity training, specifically forms of interval training.

\section{CONFLICTS OF INTEREST}

The authors confirm that this article content has no conflicts of interest.

\section{ACKNOWLEDGEMENTS}

\author{
None declared
}

\section{REFERENCES}

[1] WHO. Global recommendations on physical activity for health. 2010.

[2] WHO. The world health report 2002 - Reducing Risks, Promoting Healthy Life 2002

[3] WHO. The global burden of disease: 2004 update. 2008.

[4] Papadakis S, Moroz I. Population-level interventions for coronary heart disease prevention: what have we learned since the North Karelia project? Curr Opin Cardiol 2008; 23(5): 452-61.

[5] Beaglehole R, Bonita R, Horton R, et al. Priority actions for the non-communicable disease crisis. Lancet 2011; 377(9775): 143847.

[6] Sellers DE, Crawford SL, Bullock K, McKinlay JB. Understanding the variability in the effectiveness of community heart health programs: a meta-analysis. Soc Sci Med 1997; 44(9): 1325-39.

[7] Puska P, Salonen JT, Nissinen A, et al. Change in risk factors for coronary heart disease during 10 years of a community intervention programme (North Karelia project). Br Med J (Clin Res Ed) 1983; 287(6408): 1840-4.

[8] Abramson JH, Gofin R, Hopp C, Gofin J, Donchin M, Habib J. Evaluation of a community program for the control of cardiovascular risk factors: the CHAD program in Jerusalem. Isr J Med Sci 1981; 17(2-3): 201-12.

[9] Farquhar JW, Maccoby N, Wood PD, et al. Community education for cardiovascular health. Lancet 1977; 1(8023): 1192-5.

[10] Record NB, Harris DE, Record SS, Gilbert-Arcari J, DeSisto M, Bunnell S. Mortality impact of an integrated community cardiovascular health program. Am J Prev Med 2000; 19(1): 30-8.

[11] Farquhar JW, Fortmann SP, Flora JA, et al. Effects of communitywide education on cardiovascular disease risk factors. The Stanford Five-City Project. JAMA 1990; 264(3): 359-65.

[12] Luepker RV, Murray DM, Jacobs DR, Jr, et al. Community education for cardiovascular disease prevention: risk factor changes in the Minnesota Heart Health Program. Am J Public Health 1994; 84(9): 1383-93.

[13] Carleton RA, Lasater TM, Assaf AR, Feldman HA, McKinlay S. The Pawtucket Heart Health Program: community changes in cardiovascular risk factors and projected disease risk. Am J Public Health 1995; 85(6): 777-85.

[14] Lupton BS, Fonnebo V, Sogaard AJ, Finnmark IS. The Finnmark Intervention Study: is it possible to change CVD risk factors by community-based intervention in an Arctic village in crisis? Scand J Public Health 2003; 31(3): 178-86.

[15] Puska P. Successful prevention of noncomunicable diseases: 25 year experiences with North Karelia Project in Finland. Public Health Medicine. Public Health Med 2002; 4(1): 5-7.

[16] Salonen JT. Did the North Karelia project reduce coronary mortality? Lancet 1987; 2(8553): 269.

[17] Ford ES, Ajani UA, Croft JB, et al. Explaining the decrease in U.S. deaths from coronary disease, 1980-2000. N Engl J Med 2007; 356(23): 2388-98.

[18] Hoffmeister H, Mensink GB, Stolzenberg H, et al. Reduction of coronary heart disease risk factors in the German cardiovascular prevention study. Prev Med 1996; 25(2): 135-45.

[19] Jenum AK, Anderssen SA, Birkeland KI, et al. Promoting physical activity in a low-income multiethnic district: effects of a community intervention study to reduce risk factors for type 2 diabetes and cardiovascular disease: a community intervention reducing inactivity. Diabetes Care 2006; 29(7): 1605-12. 
[20] Luepker RV, Rastam L, Hannan PJ, et al. Community education for cardiovascular disease prevention. Morbidity and mortality results from the Minnesota Heart Health Program. Am J Epidemiol 1996; 144(4): 351-62.

[21] Young DR, Haskell WL, Jatulis DE, Fortmann SP. Associations between changes in physical activity and risk factors for coronary heart disease in a community-based sample of men and women: the Stanford Five-City Project. Am J Epidemiol 1993; 138(4): 205-16.

[22] Wang Y, Beydoun MA. The obesity epidemic in the United States-gender, age, socioeconomic, racial/ethnic, and geographic characteristics: a systematic review and meta-regression analysis. Epidemiol Rev 2007; 29: 6-28.

[23] WHO. Obesity: preventing and managing the global epidemic. Report of a WHO consultation. World Health Organ Tech Rep Ser 2000; 894: I- XII, 1-253.

[24] WHO. The challenge of obesity in the WHO European region and the strategies for response. Copenhagen: WHO 2008.

[25] Stene LC, Midthjell K, Jenum AK, et al. Prevalence of diabetes mellitus in Norway. Tidsskrift for Den Norske Laegeforening 2004; 124(11): 1511-4.

[26] Anderssen SA, Carroll S, Urdal P, Holme I. Combined diet and exercise intervention reverses the metabolic syndrome in middleaged males: results from the Oslo Diet and Exercise Study. Scand J Med Sci Sports 2007; 17(6): 687-95.

[27] Lindstrom J, Ilanne-Parikka P, Peltonen M, et al. Sustained reduction in the incidence of type 2 diabetes by lifestyle intervention: follow-up of the Finnish Diabetes Prevention Study. Lancet 2006; 368(9548):1673-9.

[28] Albright A, Franz M, Hornsby G, et al. American College of Sports Medicine position stand. Exercise and type 2 diabetes. Med Sci Sports Exerc 2000; 32(7): 1345-60.

[29] Knowler WC, Barrett-Connor E, Fowler SE, et al. Reduction in the incidence of type 2 diabetes with lifestyle intervention or metformin. N Engl J Med 2002; 246(6): 393-403.

[30] The NHS Information Centre LU. Health Survey for England 2008: Physical activity and fitness. 2009. Available at: http: //www.ic.nhs.uk/pubs/hse08physicalactivity

[31] Troiano RP, Berrigan D, Dodd KW, Masse LC, Tilert T, McDowell M. Physical activity in the United States measured by accelerometer. Med Sci Sports Exerc 2008; 40(1): 181-8.

[32] Parrott S, Godfrey C. Economics of smoking cessation. BMJ 2004; 328(7445): 947-9.

[33] Rosamond W, Flegal K, Furie K, et al. Heart Disease and Stroke Statistics--2008 Update: A Report From the American Heart Association Statistics Committee and Stroke Statistics Subcommittee. Circulation 2008; 117(4): e25-146.

[34] Weiler R, Stamatakis E. Physical activity in the UK: a unique crossroad? Br J Sports Med 2010; 44: 912-14.

[35] Norwegian Directorate of Health. Key numbers for the health sector. Norwegian Public Health Policy Report 2009.

[36] Universitty of Bergen. HEMIL-report 3/2009. 2009.

[37] Byberg L, Melhus H, Gedeborg R, et al. Total mortality after changes in leisure time physical activity in 50 year old men: 35 year follow-up of population based cohort. Br J Sports Med 2009; 43(7): 482.

[38] Wen CP, Wai JPM, Tsai MK, et al. Minimum amount of physical activity for reduced mortality and extended life expectancy: a prospective cohort study. Lancet 2011; 378(9798): 1244-53.

[39] Pescatello LS, Franklin BA, Fagard R, et al. American College of Sports Medicine position stand. Exercise and hypertension. Med Sci Sports Exerc 2004; 36(3): 533-53.

[40] Thompson PD, Buchner D, Pina IL, et al. Exercise and physical activity in the prevention and treatment of atherosclerotic cardiovascular disease: a statement from the Council on Clinical Cardiology (Subcommittee on Exercise, Rehabilitation, and Prevention) and the Council on Nutrition, Physical Activity, and Metabolism (Subcommittee on Physical Activity). Circulation 2003; 107(24): 3109-16.

[41] Gregg EW, Cauley JA, Stone K, et al. Relationship of changes in physical activity and mortality among older women. JAMA 2003; 289(18): 2379-86.

[42] Gulati M, Pandey DK, Arnsdorf MF, et al. Exercise capacity and the risk of death in women: the St James Women Take Heart Project. Circulation 2003; 108(13): 1554-9.
[43] Hakim AA, Petrovitch H, Burchfiel CM, et al. Effects of walking on mortality among nonsmoking retired men. N Engl J Med 1998; 338(2): 94-9.

[44] Keteyian SJ, Brawner CA, Savage PD, et al. Peak aerobic capacity predicts prognosis in patients with coronary heart disease. Am Heart J 2008; 156(2): 292-300.

[45] O'Connor CM, Whellan DJ, Lee KL, et al. Efficacy and safety of exercise training in patients with chronic heart failure: HFACTION randomized controlled trial. JAMA 2009; 301(14): 143950.

[46] Piepoli MF, Davos C, Francis DP, Coats AJ. Exercise training meta-analysis of trials in patients with chronic heart failure (ExTraMATCH). BMJ 2004; 328(7433): 189.

[47] Garcia-Aymerich J, Lange P, Serra I, Schnohr P, Anto JM. Timedependent confounding in the study of the effects of regular physical activity in chronic obstructive pulmonary disease: an application of the marginal structural model. Ann Epidemiol 2008; 18(10): 775-83.

[48] Booth FW, Chakravarthy MV, Gordon SE, Spangenburg EE. Waging war on physical inactivity: using modern molecular ammunition against an ancient enemy. J Appl Physiol 2002; 93(1): 330.

[49] Myers J, Prakash M, Froelicher V, Do D, Partington S, Atwood JE. Exercise capacity and mortality among men referred for exercise testing. N Engl J Med 2002; 346(11): 793-801.

[50] Kavanagh T, Mertens DJ, Hamm LF, et al. Prediction of long-term prognosis in 12169 men referred for cardiac rehabilitation. Circulation 2002 ;106(6): 666-71.

[51] Wisloff U, Nilsen TIL, Droyvold WB, Morkved S, Slordahl SA, Vatten LJ. A single weekly bout of exercise may reduce cardiovascular mortality: how little pain for cardiac gain? 'The HUNT study, Norway'. Eur J Cardiovasc Prev Rehabil 2006; 13(5): 798-804.

[52] Tjonna AE, Stolen TO, Bye A, et al. Aerobic interval training reduces cardiovascular risk factors more than a multitreatment approach in overweight adolescents. Clin Sci 2009; 116(4): 317-26.

[53] Lee DC, Sui X, Ortega FB, et al. Comparisons of leisure-time physical activity and cardiorespiratory fitness as predictors of allcause mortality in men and women. Br J Sports Med 2011; 45(6): 504-10.

[54] Lee IMM, Sesso HDS, Oguma YM, Paffenbarger RSJMD. Relative intensity of physical activity and risk of coronary heart disease. Circulation 2003; 107(8): 1110-6.

[55] llgen H, Ckenhoff A, Knapp G. Physical activity and all-cause mortality: an updated meta-analysis with different intensity categories. Int J Sports Med 2009; 30(3): 213-24.

[56] Paffenbarger RS Jr, Hyde RT, Wing AL, Hsieh CC. Physical activity, all-cause mortality, and longevity of college alumni. N Engl J Med 1986; 314(10): 605-13.

[57] Blair SN, Kohl HW III, Barlow CE, Paffenbarger RS Jr, Gibbons LW, Macera CA. Changes in physical fitness and all-cause mortality. A prospective study of healthy and unhealthy men. JAMA 1995; 273(14): 1093-8.

[58] Pekkanen J, Nissinen A, Marti B, Tuomilehto J, Punsar S, Karvonen $\mathrm{M}$. Reduction of premature mortality by high physical activity: A 20-year follow-up of middle-aged finnish men. Lancet 1987; 329(8548): 1473-7.

[59] Sassen B, Cornelissen VA, Kiers H, Wittink H, Kok G, Vanhees L. Physical fitness matters more than physical activity in controlling cardiovascular disease risk factors. Eur J Cardiovasc Prev Rehabil 2009; 16(6): 677-83.

[60] Nocon M, Hiemann T, Muller-Riemenschneider F, Thalau F, Roll S, Willich SN. Association of physical activity with all-cause and cardiovascular mortality: a systematic review and meta-analysis. Eur J Cardiovasc Prev Rehabil 2008; 15(3): 239-46.

[61] Mora S, Redberg RF, Cui Y, et al. Ability of exercise testing to predict cardiovascular and all-cause death in asymptomatic women: a 20-year follow-up of the lipid research clinics prevalence study. JAMA 2003; 290(12): 1600-7.

[62] Kodama S, Saito K, Tanaka S, et al. Cardiorespiratory fitness as a quantitative predictor of all-cause mortality and cardiovascular events in healthy men and women: a meta-analysis. JAMA 2009; 301(19): 2024-35.

[63] Farrell SW, Fitzgerald SJ, Mcauley PA, Barlow CE. Cardiorespiratory Fitness, Adiposity, and All-Cause Mortality in Women. Med Sci Sports Exerc 2010; 42(11): 2006-12. 
[64] Lee CD, Blair SN, Jackson AS. Cardiorespiratory fitness, body composition, and all-cause and cardiovascular disease mortality in men. Am J Clin Nutr 1999; 69(3): 373-80.

[65] Blair SN, Brodney S. Effects of physical inactivity and obesity on morbidity and mortality: current evidence and research issues. Med Sci Sports Exerc 1999; 31(11 Suppl): S646-62.

[66] Wisloff U, Najjar SM, Ellingsen O, et al. Cardiovascular risk factors emerge after artificial selection for low aerobic capacity. Science 2005; 307(5708): 418-20.

[67] Myers J, Kaykha A, George S, et al. Fitness versus physical activity patterns in predicting mortality in men. Am J Med 2004; 117(12): 912-8.

[68] Aspenes ST, Nilsen TIL, Skaug EA, et al. Peak oxygen uptake and cardiovascular risk factors in 4,631 healthy women and men. Med Sci Sports Exerc 2011; 43: 1465-73.

[69] Sofi F, Capalbo A, Cesari F, Abbate R, Gensini GF. Physical activity during leisure time and primary prevention of coronary heart disease: an updated meta-analysis of cohort studies. Eur $\mathbf{J}$ Cardiovasc Prev Rehabil 2008; 15(3): 247-57.

[70] Manson JE, Greenland P, LaCroix AZ, et al. Walking Compared with Vigorous Exercise for the Prevention of Cardiovascular Events in Women. N Engl J Med 2002; 347(10): 716-25.

[71] Lollgen H, Bockenhoff A, Knapp G. Physical activity and all-cause mortality: an updated meta-analysis with different intensity categories. Int J Sports Med 2009; 30(3): 213-24.

[72] Cornelissen VA, Arnout J, Holvoet P, Fagard RH. Influence of exercise at lower and higher intensity on blood pressure and cardiovascular risk factors at older age. J Hypertens 2009; 27(4): 75362.

[73] Wisloff U, Stoylen A, Loennechen JP, et al. Superior cardiovascular effect of aerobic interval training versus moderate continuous training in heart failure patients: a randomized study. Circulation 2007; 115(24): 3086-94.

[74] Kemi OJ, Wisloff U. High-intensity aerobic exercise training improves the heart in health and disease. J Cardiopulm Rehabil Prev 2010; 30(1): 2-11.

[75] Rognmo O, Hetland E, Helgerud J, Hoff J, Slordahl SA. High intensity aerobic interval exercise is superior to moderate intensity exercise for increasing aerobic capacity in patients with coronary artery disease. Eur J Cardiovasc Prev Rehabil 2004; 11(3): 216-22.

[76] Winett RA, Wojcik JR, Fox LD, Herbert WG, Blevins JS, Carpinelli RN. Effects of Low Volume Resistance and Cardiovascular Training on Strength and Aerobic Capacity in Unfit Men and Women: A Demonstration of a Threshold Model. J Behav Med 2003; 26(3): 183-95.

[77] Tjonna AE, Megaard LI, Bartnes TA, Jenssen BM, Winett RA, Wisloff $U$. The Effects of a 4-minute interval training protocol on cardiorespiratory and metabolic risk factors. paper presented at the at the 32nd annual meeting \& scientific sessions of the society of behavioral medicine, Washington DC., April 29, 2011.

[78] Gibala MJ, McGee SL. Metabolic adaptations to short-term highintensity interval training: a little pain for a lot of gain? Exerc Sport Sci Rev 2008; 36(2): 58-63.

[79] McLaren L, Ghali LM, Lorenzetti D, Rock M. Out of context? Translating evidence from the North Karelia project over place and time. Health Educ Res 2007; 22(3): 414-24.

[80] Artinian NT, Fletcher GF, Mozaffarian D, et al. Interventions to promote physical activity and dietary lifestyle changes for cardiovascular risk factor reduction in adults: A Scientific Statement From the American Heart Association. Circulation 2010; 122(4): 406-41.

[81] Phillips SM, Winett RA. Uncomplicated resistance training and health-related outcomes: evidence for a public health mandate. Curr Sports Med Rep 2010; 9(4): 208-13.
[82] Puska P. Fat and heart disease: yes we can make a change--the case of North Karelia (Finland). Ann Nutr Metab 2009; 54(Suppl 1): 338.

[83] Weinehall L, Hellsten G, Boman K, Hallmans G, Asplund K, Wall S. Can a sustainable community intervention reduce the health gap?--10-year evaluation of a Swedish community intervention program for the prevention of cardiovascular disease. Scand J Public Health 2001; 59(suppl 56): 68.

[84] Chen J, Wu X, Gu D. Hypertension and cardiovascular diseases intervention in the capital steel and iron company and Beijing Fangshan community. Obes Rev 2008; 9(Suppl 1): 142-5.

[85] Nafziger AN, Erb TA, Jenkins PL, Lewis C, Pearson TA. The Otsego-Schoharie healthy heart program: prevention of cardiovascular disease in the rural US. Scand J Public Health 2001; Suppl 56(21): 32.

[86] Lupton BS, Fonnebo V, Sogaard AJ, Langfeldt E. The Finnmark Intervention Study. Better health for the fishery population in an Arctic village in North Norway. Scand J Prim Health Care 2002; 20(4): 213-8.

[87] Khavjou OA, Finkelstein EA, Will JC. The impact of medication use in a multicomponent intervention: results from the WISEWOMAN program. Am J Health Promot 2007; 21(4): 267-73.

[88] Dowse GK, Gareeboo H, Alberti KG, et al. Changes in population cholesterol concentrations and other cardiovascular risk factor levels after five years of the non-communicable disease intervention programme in Mauritius. Mauritius Non-communicable Disease Study Group. BMJ 1995; 311(7015): 1255-9.

[89] Muntoni S, Stabilini L, Stabilini M, Muntoni S. Results of a fiveyear community-based programme for cardiovascular disease prevention: the ATS-Sardegna Campaign. Eur J Epidemiol 1999; 15(1): 29-34.

[90] Schuit AJ, Wendel-Vos GCW, Verschuren WMM, et al. Effect of 5-Year Community Intervention Hartslag Limburg on Cardiovascular Risk Factors. Am J Prev Med 2006; 30(3): 237-42.

[91] Gutzwiller F, Nater B, Martin J. Community-based primary prevention of cardiovascular disease in Switzerland: methods and results of the National Research Program (NRP 1A). Prev Med 1985; 14(4): 482-91.

[92] Egger G, Fitzgerald W, Frape G, et al. Results of large scale media antismoking campaign in Australia: North Coast "Quit for Life" programme. Br Med J Clin Res Ed 1983; 287(6399): 1125-8.

[93] Tudor-Smith C, Nutbeam D, Moore L, Catford J. Effects of the Heartbeat Wales programme over five years on behavioural risks for cardiovascular disease: quasi-experimental comparison of results from Wales and a matched reference area. BMJ 1998; 316(7134): 818-22.

[94] Brownson RC, Smith CA, Pratt M, et al. Preventing cardiovascular disease through community-based risk reduction: the Bootheel Heart Health Project. Am J Public Health 1996; 86(2): 206-13.

[95] Kloek GC, van Lenthe FJ, van Nierop PW, Koelen MA, Mackenbach JP. Impact evaluation of a Dutch community intervention to improve health-related behaviour in deprived neighbourhoods. Health Place 2006; 12(4): 665-77.

[96] Osler M, Jespersen NB. The effect of a community-based cardiovascular disease prevention project in a Danish municipality. Dan Med Bull 1993; 40(4): 485-9.

[97] O'Loughlin JL, Paradis G, Gray-Donald K, Renaud L. The impact of a community-based heart disease prevention program in a lowincome, inner-city neighborhood. Am J Public Health 1999; 89(12): 1819-26.

[98] Eaton CB, Lapane KL, Garber CE, Gans KM, Lasater TM, Carleton RA. Effects of a community-based intervention on physical activity: the Pawtucket Heart Health Program. Am J Public Health 1999; 89(1741): 1744.

(C) Rehn et al.; Licensee Bentham Open.

This is an open access article licensed under the terms of the Creative Commons Attribution Non-Commercial License (http://creativecommons.org/licenses/ by-nc/3.0/) which permits unrestricted, non-commercial use, distribution and reproduction in any medium, provided the work is properly cited. 